\title{
Downregulation of Epstein-Barr virus-induced gene 3 is associated with poor prognosis of hepatocellular carcinoma after curative resection
}

\author{
QINGJIE SONG ${ }^{1 *}, \mathrm{XI} \mathrm{CHEN}^{2 *}$, WEIDONG HU${ }^{2}$, GUANGLIN MEI $^{2}, \mathrm{XIAOBING} \mathrm{YANG}^{2}$ and $\mathrm{HAN} \mathrm{WU}^{2}$ \\ ${ }^{1}$ Department of General Surgery, The Qidong People's Hospital and Qidong Liver Cancer Institute, Nantong, Jiangsu 226200; \\ ${ }^{2}$ Department of General Surgery, The Affiliated Hospital of Nantong University, Nantong, Jiangsu 226001, P.R. China
}

Received July 10, 2017; Accepted January 19, 2018

DOI: $10.3892 / \mathrm{ol} .2018 .8272$

\begin{abstract}
Epstein-Barr virus-induced gene 3 (EBI3) encodes a secretory glycoprotein, and has previously been identified as upregulated in various types of tumors. The presnet study examined the clinical significance of EBI3 expression for predicting tumor recurrence and survival after resection in hepatocellular carcinoma (HCC). EBI3 expression in various HCC cell lines and in 20 pairs of tumor and peritumor tissue samples were detected using western blot analysis. Immunohistochemical staining using tissue microarray with 312 samples from randomly selected patients with HCC who underwent surgery. Survival analysis was performed using univariate and multivariate analyses. EBI3 protein level was higher in L-02 cells and in peri-tumor tissues compared with tumor tissues. Immunohistochemical staining of EBI3 was reduced in HCC tissues in comparison with adjacent normal tissues and significantly associated with tumor invasive characteristics, including tumor thrombus, poor differentiation and large size. Notably, the results suggested that EBI3 was a predictor for tumor recurrence and patient survival, and multivariate analysis indicated EBI3 to be an independent prognostic factor. Even in early-stage disease, low EBI3 expression was also independently associated with increased tumor recurrence and shortened survival. Downregulation of EBI3 in HCC indicated aggressive tumor behaviors and predicted a more severe clinical outcome, which suggests that EBI2 may be a useful biomarker to identify patients at high risk of post-operative recurrence.
\end{abstract}

Correspondence to: Professor Han Wu or Dr Xiaobing Yang, Department of General Surgery, The Affiliated Hospital of Nantong University, 20 Xisi Road, Nantong, Jiangsu 226001, P.R. China

E-mail: wuhan_m@hotmail.com

E-mail: yxb319351240@outlook.com

*Contributed equally

Key words: Epstein-Barr virus-induced gene 3, hepatocellular carcinoma, prognosis, progression, biomarker

\section{Introduction}

As a member of the malignancies globally with most prevalence, hepatocellular carcinoma (HCC) has an escalated associated mortality and morbidity recently (1). In spite of improvements in clinical therapy and surveillance strategies, HCC's prognosis keeps unsatisfied for great incidence of metastasis and recurrence in patients with HCC after surgical resection (2). It is still challenging to predict recurrence for patients who have undergone surgical resection. Though HCC has several clinicopathological features like vascular invasion and tumor multifocality which do good to assess HCC patients' prognosis, they are not able to meet requirements in clinic for predicting HCC course precisely (3). Thus, various biomarkers were explored to make prediction of HCC outcomes, however, no one was accepted or used widely in clinical practices.

In foregoing researches, Epstein-Barr virus-induced gene 3 (EBI3) that was initiatively cloned to be a gene produced within Epstein-Barr virus-transformed B cells via the oncogene underlying membrane protein 1 presented a limited expression pattern within B-cell lymphoma (4). Recently researches showed that as one of the interleukin-12 IL-12) family structural subunits, EBI3 can form a heterodimer with IL-12p35 and IL-27p28 subunit to build IL-35 and IL-27, respectively (5). Nevertheless, IL-35 inhibits whereas IL-27 stimulates anti-tumor responses of $\mathrm{T}$ lymphocytes in the tumor local microenvironment (6-8). So, as a dominant subunit of IL-27 or IL-35, EBI3 may participate in the development or progression of cancers (9). Up to now, the information about the expression pattern of EBI3 and its potential predicting prognosis function on cancers are still limited and controversial. Accumulating evidences suggested that upregulated expression of EBI3 was associated with tumor progression and metastasis in a variety of cancers, including lung cancer (10), gastric cancer (11), cervical cancer (12), nasopharyngeal carcinoma (13) and pancreatic cancer (14). Knockdown of EBI3 inhibited lung cancer cell proliferation, while upregulation of EBI3 promoted lung cancer cell growth (10). And tumor-derived IL-35/EBI3 could promote tumor development by enhancing of tumor angiogenesis, myeloid cell accumulation, and 
suppressing tumor immunity (15). In addition, some studies demonstrated that high expression levels of EBI3 were associated with unfavorable prognosis in many types of cancer patients $(10,12,16)$. Nevertheless, the current research about the significance of IL-35 in HCC seems to be contradictory $(17,18)$.

Therefore, in order to explore the clinical importance of EBI3 and its potential as a prognostic biomarker as well as a therapeutic target, we used immunohistochemistry to detect the expression of EBI3 in HCC TMAs with enlargement sample size and appraised its predictive significance in the prognosis of HCC patients receiving radical surgery resection.

\section{Patients and methods}

Patients and specimens. Twenty HCC tissues samples used in Western blot assay, which were stored at $-80^{\circ} \mathrm{C}$ in a refrigerator, were randomly collected from patients suffering from liver resection at the Affiliated Hospital of Nantong University (Nantong, China) from 2015 to 2016. Tumor specimens applied to tissue microarrays (TMAs) analysis were consecutively chosen among 312 HCC patients undergoing liver resection in our hospital between 2011 and 2014. For these samples, $5-\mu$ m-thick formalin-fixed paraffin-embedded slides were formulated in accordance with the protocol of the Department of Pathology of our hospital. The patients' clinicopathologic features were outlined in Table I. The enrollment criteria for all patients in the study were i) $\mathrm{HCC}^{\prime}$ distinctive pathologic diagnosis; ii) with no anticancer treatment and distant metastases before surgery; iii) underwent curative and primary resection for HCC; and iv) availability of whole clinicopathologic and follow-up data. Liver function was assessed by Child-Pugh classification. The determination of tumor stage was based on the classification system of American Joint Committee on Cancer/International Union Against Cancer tumor-node-metastasis (TNM) in 2002. Tumor differentiation was based by the Edmondson grading system. According to a uniform guideline, postoperative treatments and surveillance were described in our previous study (19). Data were censored at last follow-up for patients without relapse or death. The definition of time to recurrence (TTR) was time from surgery to first detection of tumor recurrence. The definition of overall survival (OS) was time from surgery to death for any inducement. The study protocol was approved by the Human Research Ethics Committee of Nantong University Affiliated Hospital and conformed to the provisions of the Declaration of Helsinki in 1995. Written informed consent was obtained from all study participants.

Postoperative cumulative recurrence and survival rates (in brackets) at 1, 3, and 5 years were $22.8 \%$ (89.7\%), $42.9 \%$ (71.9\%), and $56.8 \%(59.9 \%)$ for the whole study population. At last follow-up, either the recurrence of the disease $(n=74)$ or complications related to surgery without recurrence $(n=44)$ caused $118(37.8 \%)$ patients to die. The mean duration of follow-up of the remaining 194 patients was 37.8 months (range: 17.4-58.9 months, standard deviation: \pm 8.4 ).

TMAs construction and immunohistochemistry. The construction of TMAs were done as previously described (19).
Table I. Clinicopathological characteristics of patients with hepatocellular carcinoma.

\begin{tabular}{|c|c|c|}
\hline Indexes & $\mathrm{N}($ total $=312)$ & $\%$ \\
\hline \multicolumn{3}{|l|}{ Age (years) } \\
\hline$\leq 52$ & 155 & 49.68 \\
\hline$>52$ & 157 & 50.32 \\
\hline \multicolumn{3}{|l|}{ Sex } \\
\hline Male & 47 & 15.06 \\
\hline Female & 265 & 84.94 \\
\hline \multicolumn{3}{|c|}{ Liver cirrhosis } \\
\hline No & 33 & 10.58 \\
\hline Yes & 279 & 89.42 \\
\hline \multicolumn{3}{|l|}{ HBsAg } \\
\hline Negative & 52 & 16.67 \\
\hline Positive & 260 & 83.33 \\
\hline \multicolumn{3}{|c|}{ Tumor thrombus } \\
\hline No & 227 & 72.76 \\
\hline Yes & 85 & 27.24 \\
\hline \multicolumn{3}{|l|}{$\gamma-\mathrm{GT}(\mathrm{U} / \mathrm{l})$} \\
\hline$\leq 54$ & 148 & 47.44 \\
\hline$>54$ & 164 & 52.56 \\
\hline \multicolumn{3}{|c|}{$\mathrm{AFP}(\mathrm{ng} / \mathrm{ml})$} \\
\hline$\leq 20$ & 121 & 38.78 \\
\hline$>20$ & 191 & 61.22 \\
\hline
\end{tabular}

Child-Pugh score

A

309

99.04

B

0.96

Tumor differentiation

$\begin{array}{lrr}\text { I-II } & 232 & 74.36 \\ \text { III-IV } & 80 & 25.64\end{array}$

Tumor size $(\mathrm{cm})$

$\leq 5 \quad 207 \quad 66.35$

$>5$

33.65

Tumor number

$\begin{array}{lll}\text { Single } & 270 & 86.54\end{array}$

$\begin{array}{lll}\text { Multiple } & 42 & 13.46\end{array}$

Tumor encapsulation

Complete $\quad 172 \quad 55.13$

$\begin{array}{lll}\text { None } & 140 & 44.87\end{array}$

TNM stage

$\begin{array}{lll}\text { I } & 138 & 44.23\end{array}$

II-III $174 \quad 55.77$

BCLC stage

$\begin{array}{lll}\text { A } & 212 & 67.95\end{array}$

$\begin{array}{lll}\text { B-C } & 100 & 32.05\end{array}$

AFP, alpha-fetoprotein; $\gamma$-GT, $\gamma$-glutamyl transferase; HBsAg, hepatitis B surface antigen; TNM stage, tumor node metastasis stage; BCLC stage, the Barcelona Clinic Liver Cancer stage. 
A
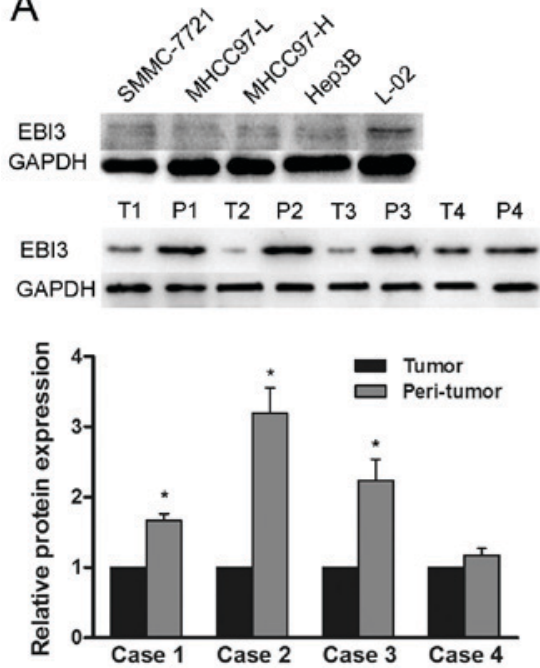

$\mathrm{B}$

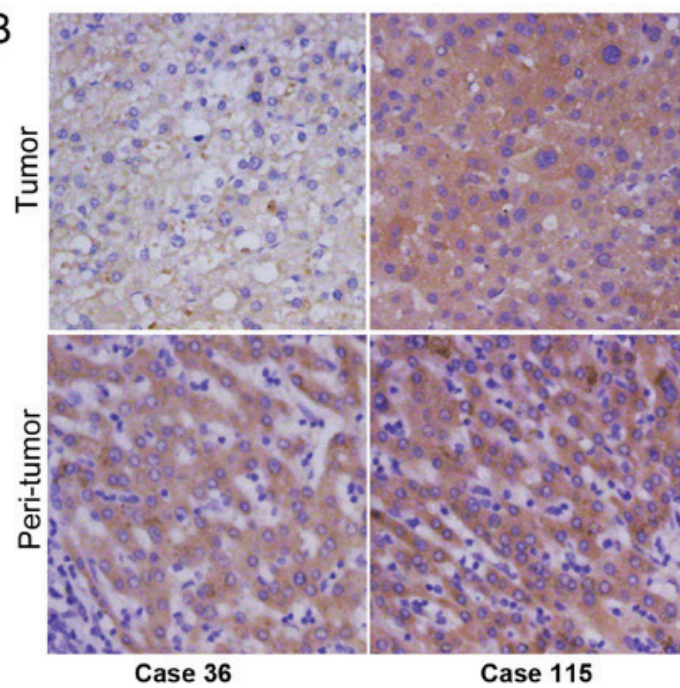

Figure 1. Expression of EBI3 in human hepatoma cell lines and tissue samples. (A) EBI3 was detected by western blot analysis in 5 hepatoma cell lines, 20 HCC tissues and corresponding peritumoral tissues and quantitative results of the western blot analysis, GAPDH served as a loading control $\mathrm{P}<0.05$ vs. tumor. (B) Representative immunohistochemical staining of EBI3 in tissue microarrays (magnification, x200). EBI3, Epstein-Barr virus-induced gene 3; HCC, hepatocellular carcinoma; GAPDH, glyceraldehyde-3-phosphate dehydrogenase.

The TMAs were derived from two typical histological cores out of blocks of HCC tumor tissue embedded in paraffin using UT06 Quick-Ray Manual Tissue Microarrayer (Unitma Co., Ltd., Seoul, South Korea). Pathological analysis was reviewed by two independent skillful pathologists for all specimens.

Immunohistochemistry (IHC) analysis got performed according to the standard protocols of Envision ${ }^{+\mathrm{TM}}$ peroxidase kit (Dako, Carpinteria, CA, USA). Being deparaffinizated and rehydrated, the tissue sections were subsequently heated with $1 \mathrm{X}$ sodium citrate solution at $100^{\circ} \mathrm{C}$ for $30 \mathrm{~min}$, and then washed 3 times. Following immerged in $3 \% \mathrm{H}_{2} \mathrm{O}_{2}$ for $15 \mathrm{~min}$, the tissue sections were incubated with the rabbit polyclonal anti-human EBI3 antibody (dilution 1:200; sc-32,868; Santa Cruz Biotechnology, Inc., Dallas, TX, USA) overnight at $4^{\circ} \mathrm{C}$. A two-step incubation with a secondary antibody was performed using an immunohistochemistry universal kit (ZSGB-BIO; Beijing, China). Incubation of samples were with 3,3'-diaminobenzidine plus (Dako), then counterstained by hematoxylin, dehydrated by graded alcohol, cleared in xylene, and finally placed into permanent mounting media with a cover slip.

All cases were calculated and scored by researchers who blinded to the clinical characteristics of the patients. Taking into account not only the staining intensity but also the percentage of cells that stained at this intensity, scoring on EBI3 expression was calculated by the semi-quantitative H-score method. The score of staining intensity was 0 , no stain; $1+$, weak stain; $2+$, moderate stain; or $3+$, intense stain. The intensity score determined and multiplied the percentage of cells staining at each intensity to create a score of intensity percentage. The scores representing the percentage of positive cells were as follows: $0,0-20 \% ; 1,21-50 \%, 2,51-75 \% ; 3,76-100 \%$. The calculation of final staining scores was adding the four scores of intensity percentage. It had a minimum value of 0 as no stain, as well as a maximum value of 300 as $100 \%$ of cells with a $3+$ staining intensity.
Cell culture. HCC cell lines Hep3B and SMMC-7721 were obtained from the General Surgery Institute of our hospital. HCC cell lines MHCC97-L, and MHCC97-H with low and high metastatic potential, as well as normal human hepatic L-02 cells were purchased from Liver Cancer Institute, Fudan University (Shanghai, China). These cells were cultured in Dulbecco's modified Eagle's medium (DMEM; Gibco, NY, USA) with the supplement of $10 \%$ fetal bovine serum (Hyclone, Logan, UT, USA) and penicillin-streptomycin (Invitrogen; Carlsbad, $\mathrm{CA}, \mathrm{USA}$ ) at $37^{\circ} \mathrm{C}$ in $5 \% \mathrm{CO}_{2}$.

Western blot analysis. Tissue or cell lysates were produced and total proteins were isolated employing standard sodium dodecyl sulfate polyacrylamide gel electrophoresis (SDS-PAGE) and then were transfered to polyvinylidene difluoride (PVDF) membranes (Millipore, Billerica, MA, USA) which were washed and blocked before incubation with anti-EBI3 (1:400, polyclonal, rabbit anti-human; Santa Cruz Biotechnology Inc.), subsequently incubated with horseradish peroxidase (HRP), as conjugated secondary antibodies. An improved chemiluminescence assay was used to detect the reactions. Glyceraldehyde-3-phosphate dehydrogenase (GAPDH) was applied as a loading control. Western blot quantifications were performed using Image $\mathrm{J}$ software $(\mathrm{NIH}$, Bethesda, MD, USA).

Statistical analysis. The statistical analyses were performed using SPSS 22.0 (IBM Corporation, Armonk, NY, USA). X-tile software (Rimm Lab at Yale University, http:// medicine.yale.edu/lab/rimm/research/software.aspx) was used to determine the cutoff values for high or low EBI3 expression (20). The relationship between EBI3 expression and clinicopathologic features was assayed using the $\chi^{2}$ test. Survival curves were speculated by the Kaplan-Meier method and compared by log-rank test. Univariate and multivariate analyses were made by Cox-regression model, where all the clinicopathologic characteristics were functioned as 

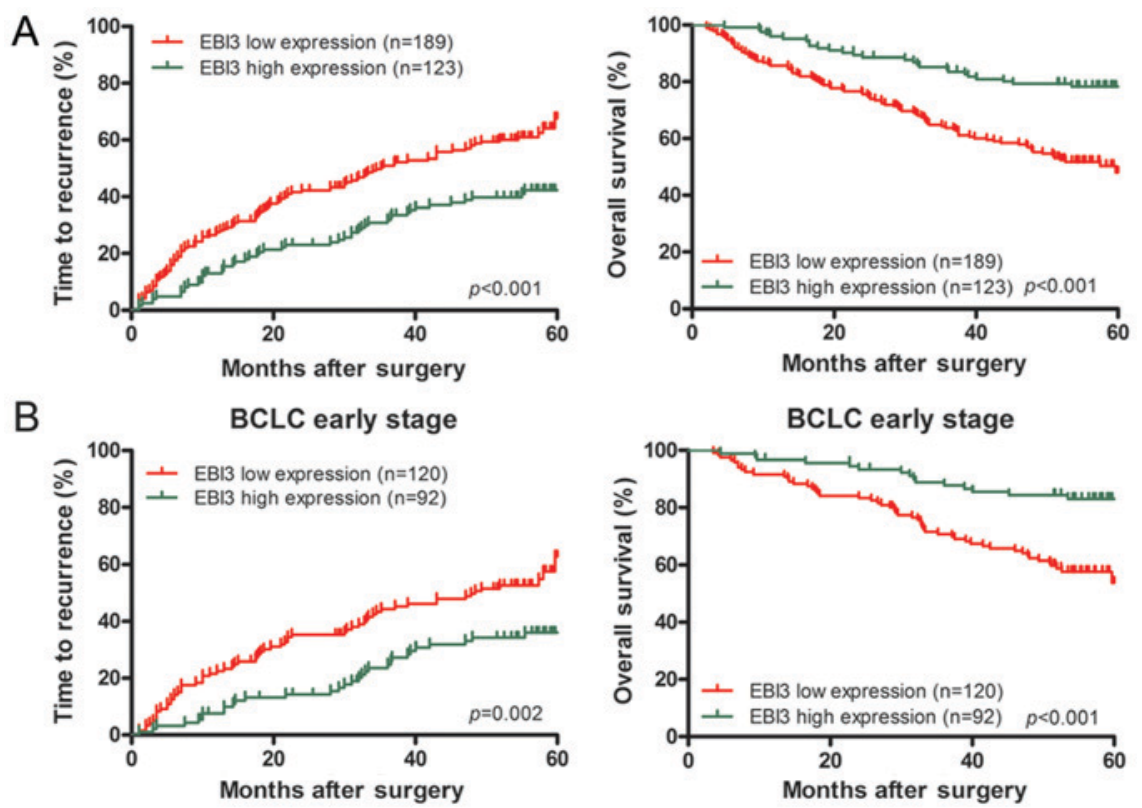

Figure 2. Kaplan-Meier analysis of survival differences in HCC patients. Difference of time to recurrence and overall survival for EBI3 in early-stage patients (A) and in all population (B). EBI3, Epstein-Barr virus-induced gene 3; HCC, hepatocellular carcinoma.

covariates. $\mathrm{P}<0.05$ (two-tailed) was considered to indicate a statistically significant difference.

\section{Results}

EBI3 expression pattern in HCC cell lines and tissue samples. Western blot assay revealed constitutive EBI3 expression in 6 human hepatoma cell lines examined. The expression of EBI3 was significantly upregulated in L-02 compared with that in HCC cells MHCC97-H, MHCC97-L, and SMMC-7721 with different metastatic potential. We found that protein expression of EBI3 was significantly downregulated in tumors in comparison with the one in relevant peritumoral liver tissues (Fig. 1A). Immunohistochemical analysis showed that the staining pattern of EBI3 was mainly cytoplasmic with week or moderate staining in tumor tissues (Fig. 1B).

Relationship of EBI3 with clinicopathologic features. We speculated the correlationship between the expression of EBI3 and the clinicopathologic characteristics in HCC patients of study set. As the Table II showed, the downregulated EBI3 was significantly correlated with high AFP level (>20 ng/ml, $\mathrm{P}=0.001$ ), poor differentiation (III-IV, $\mathrm{P}<0.001$ ), large tumor size $(>5 \mathrm{~cm}, \mathrm{P}=0.011)$, tumor thrombus $(\mathrm{P}=0.027)$, and advanced stage tumor (BCLC stages $\mathrm{B}-\mathrm{C}, \mathrm{P}=0.037$; TNM stage II-III, $\mathrm{P}=0.013)$.

EBI3 expression and patient prognosis. According to data analysis of $\mathrm{X}$-tile, the study set $(\mathrm{n}=312)$ was divided into $\mathrm{EBI} 3$ low expression group (a score of from 0 to $140, n=189,60.6 \%$ ) and EBI3 high expression group (a score of 141-300, $n=123$, $39.4 \%$ ) using a cutoff point of 140 .

Analysis of survival showed that lower EBI3 level was related with worse patient outcome. The median TTR was significantly reduced among EBI3 protein-low patients (35.17 \pm 4.33 months, vs. $45.33 \pm 1.95$ months for high levels,
$\mathrm{P}<0.001)$. The median OS was substantially reduced among patients with low EBI3 protein (43.26 \pm 1.56 months vs. 53.68 \pm 1.43 months for high levels, $\mathrm{P}<0.001)$. Postoperative recurrence rates of $\mathrm{HCC}$ patients with low and high expression (in brackets) of EBI3 at 1, 3, and 5 years were $26.0 \%$ (4.8\%), $50.5 \%(15.9 \%)$, and $68.5 \%(42.3 \%)$. Postoperative OS rates of HCC patients with low and high expression (in brackets) of $\mathrm{EBI} 3$ at 1, 3, and 5 years were $85.7 \%$ (95.9\%), 63.8\% (84.4\%), and $48.1 \%(78.3 \%)$. Univairate analysis illustrated that downregulated of EBI3 was significantly associated with TTR $(\mathrm{P}<0.001)$ and $\mathrm{OS}(\mathrm{P}<0.001)$ (Fig. 2A; Table III). Multivariate analysis demonstrated that EBI3 was an independent predictor for TTR [hazard ratio $(\mathrm{HR})=0.634,95 \%$ confidential interval $(\mathrm{CI})=0.446-0.901, \mathrm{P}=0.013)$ and $\mathrm{OS}(\mathrm{HR}=0.452$, 95\% CI=0.290-0.704, P=0.001] (Table III). In addition, apart from EBI3, tumor size was associated with OS, and Child Pugh score and tumor size were correlated with TTR in the multivariate analysis (Table III).

In addition, because BCLC stage represented the different stages of HCC progression, subgroup analysis was done for a comprehensive knowledge about EBI3 function within different stages. In early HCC (BCLC A stage), univairate analysis showed that downregulated EBI3 was significantly associated with TTR ( $\mathrm{P}=0.003)$ and OS $(\mathrm{P}<0.001)$ (Fig. 2B). Multivariate analysis demonstrated that EBI3 was at high risk of poor TTR $(\mathrm{HR}=0.553, \mathrm{P}=0.007)$ and $\mathrm{OS}(\mathrm{HR}=0.388$, $\mathrm{P}=0.001$ ) (Table III).

Furthermore, EBI3 downregulated expression had prognostic values of TTR in the subgroup of HCC patients with large tumor $(>5 \mathrm{~cm}, \mathrm{P}=0.008)$, single tumor $(\mathrm{P}<0.001)$, tumor thrombus $(\mathrm{P}=0.032)$, tumor differentiation (I-II, $\mathrm{P}=0.001)$ or incomplete tumor encapsulation $(\mathrm{P}=0.025)$ (Fig. 3). Similarly, EBI3 could predict OS in the subsets of HCC patients with large tumor $(>5 \mathrm{~cm} ; \mathrm{P}<0.001)$, single tumor $(\mathrm{P}<0.001)$, tumor thrombus $(\mathrm{P}=0.031)$, tumor differentiation $(\mathrm{I}-\mathrm{II}, \mathrm{P}<0.001)$ or incomplete tumor encapsulation $(\mathrm{P}<0.001)$ (Fig. 4). 
Table II. Correlation of clinicopathologic characteristics with EBI3 expression

\begin{tabular}{|c|c|c|c|c|c|}
\hline \multirow[b]{2}{*}{ Characteristic } & \multicolumn{5}{|c|}{ EBI3 expression $(n=312)$} \\
\hline & Total & Low & High & P-value & $\chi^{2}$ \\
\hline \multicolumn{6}{|l|}{ Age (years) } \\
\hline$\leq 52$ & 155 & 97 & 58 & 0.472 & 0.5178 \\
\hline$>52$ & 157 & 92 & 65 & & \\
\hline \multicolumn{6}{|l|}{$\operatorname{Sex}$} \\
\hline Female & 47 & 27 & 20 & 0.634 & 0.2270 \\
\hline Male & 265 & 162 & 103 & & \\
\hline \multicolumn{6}{|l|}{ HBsAg } \\
\hline No & 52 & 35 & 17 & 0.277 & 1.1837 \\
\hline Yes & 260 & 154 & 106 & & \\
\hline \multicolumn{6}{|l|}{$\operatorname{AFP}(\mathrm{ng} / \mathrm{ml})$} \\
\hline$\leq 20$ & 121 & 59 & 62 & 0.001 & 11.5567 \\
\hline$>20$ & 191 & 130 & 61 & & \\
\hline \multicolumn{6}{|l|}{ Liver cirrhosis } \\
\hline No & 33 & 19 & 14 & 0.709 & 0.1392 \\
\hline Yes & 279 & 170 & 109 & & \\
\hline \multicolumn{6}{|l|}{$\gamma$-GT (U/L) } \\
\hline$\leq 54$ & 148 & 85 & 63 & 0.280 & 1.1658 \\
\hline$>54$ & 164 & 104 & 60 & & \\
\hline \multicolumn{6}{|c|}{ Child-Pugh score } \\
\hline A & 309 & 186 & 123 & 0.160 & 1.9713 \\
\hline B & 3 & 3 & 0 & & \\
\hline \multicolumn{6}{|c|}{ Tumor differentiation } \\
\hline I-II & 232 & 126 & 106 & $<0.001$ & 14.8784 \\
\hline III-IV & 80 & 63 & 17 & & \\
\hline \multicolumn{6}{|c|}{ Tumor size $(\mathrm{cm})$} \\
\hline$\leq 5$ & 207 & 115 & 92 & 0.011 & 6.4941 \\
\hline$>5$ & 105 & 74 & 31 & & \\
\hline \multicolumn{6}{|l|}{ Tumor number } \\
\hline Single & 270 & 162 & 108 & 0.597 & 0.2795 \\
\hline Multiple & 42 & 27 & 15 & & \\
\hline \multicolumn{6}{|l|}{ Encapsulation } \\
\hline None & 172 & 101 & 71 & 0.457 & 0.5529 \\
\hline Complete & 140 & 88 & 52 & & \\
\hline \multicolumn{6}{|c|}{ Tumor thrombus } \\
\hline No & 227 & 129 & 98 & 0.027 & 4.9037 \\
\hline Yes & 85 & 60 & 25 & & \\
\hline \multicolumn{6}{|l|}{ TNM stage } \\
\hline I & 138 & 73 & 65 & 0.013 & 6.1089 \\
\hline II-III & 174 & 116 & 58 & & \\
\hline \multicolumn{6}{|l|}{ BCLC stage } \\
\hline A & 212 & 120 & 92 & 0.037 & 4.3722 \\
\hline $\mathrm{B} / \mathrm{C}$ & 100 & 69 & 31 & & \\
\hline
\end{tabular}

Statistical analyses were performed using the $\chi^{2}$ test. AFP, alpha-fetoprotein; HBsAg hepatitis B surface antigen; $\gamma$-GT, $\gamma$-glutamyl transferase; BCLC stage, the Barcelona Clinic Liver Cancer stage. 
Table III. Univariate and multivariate analyses of factors associated with survival and recurrence and early stage.

\begin{tabular}{|c|c|c|c|c|c|c|c|c|}
\hline \multirow[b]{3}{*}{ Variables } & \multicolumn{4}{|c|}{ TTR } & \multicolumn{4}{|c|}{ OS } \\
\hline & \multirow{2}{*}{$\frac{\text { Univariate }}{\text { P-value }}$} & \multicolumn{3}{|c|}{ Multivariate } & \multirow{2}{*}{$\frac{\text { Univariate }}{\text { P-value }}$} & \multicolumn{3}{|c|}{ Multivariate } \\
\hline & & P-value & HR & $95 \% \mathrm{CI}$ & & P-value & HR & $95 \% \mathrm{CI}$ \\
\hline \multicolumn{9}{|l|}{ Early stage } \\
\hline $\begin{array}{l}\text { AFP level, } \mathrm{ng} / \mathrm{ml} \\
(\leq 20 \text { vs. }>20)\end{array}$ & NS & NA & & & 0.035 & NS & & \\
\hline $\begin{array}{l}\text { Tumor differentiation } \\
\text { (I-II vs. III-IV) }\end{array}$ & NS & NA & & & NS & NA & & \\
\hline $\begin{array}{l}\text { Tumor size }, \mathrm{cm} \\
(\leq 5 \mathrm{vs} .>5)\end{array}$ & $<0.001$ & $<0.001$ & 2.089 & $1.381-3.159$ & $<0.001$ & $<0.001$ & 3.345 & $2.053-5.452$ \\
\hline $\begin{array}{l}\text { Tumor number } \\
\text { (single vs. multiple) }\end{array}$ & NS & NA & & & NS & NA & & \\
\hline $\begin{array}{l}\text { Encapsulation } \\
\text { (complete vs. none) }\end{array}$ & NS & NA & & & NS & NA & & \\
\hline EBI3 (low vs. high) & 0.003 & 0.007 & 0.553 & $0.359-0.851$ & $<0.001$ & $0.001^{*}$ & 0.388 & $0.17-0.694$ \\
\hline \multicolumn{9}{|l|}{ TMAs assay } \\
\hline $\begin{array}{l}\text { Child-Pugh score } \\
\text { (A vs. B) }\end{array}$ & 0.008 & 0.013 & 4.909 & $1.402-17.192$ & NS & NA & & \\
\hline $\begin{array}{l}\text { AFP level, ng/ml } \\
(\leq 20 \text { vs. }>20)\end{array}$ & 0.021 & NS & & & 0.007 & NS & & \\
\hline $\begin{array}{l}\text { Liver cirrhosis } \\
\text { ( no vs. yes) }\end{array}$ & NS & NA & & & NS & NA & & \\
\hline $\begin{array}{l}\text { Tumor differentiation } \\
\text { (I-II vs. III-IV) }\end{array}$ & NS & NA & & & NS & NA & & \\
\hline $\begin{array}{l}\text { Tumor size }, \mathrm{cm} \\
(\leq 5 \text { vs. }>5)\end{array}$ & $<0.001$ & 0.046 & 1.607 & $1.008-2.563$ & $<0.001$ & $<0.001$ & 3.020 & $1.796-5.078$ \\
\hline $\begin{array}{l}\text { Tumor thrombus } \\
\text { (no vs. yes) }\end{array}$ & $<0.001$ & NS & & & $<0.001$ & NS & & \\
\hline $\begin{array}{l}\text { Encapsulation } \\
\text { (complete vs. none) }\end{array}$ & NS & NA & & & NS & NA & & \\
\hline $\begin{array}{l}\text { Tumor number } \\
\text { (single vs. multiple) }\end{array}$ & 0.032 & NS & & & NS & NA & & \\
\hline TNM stage (I vs. II-III) & $<0.001$ & NS & & & $<0.001$ & NS & & \\
\hline BCLC stage (A vs. B-C) & $<0.001$ & NS & & & $<0.001$ & NS & & \\
\hline EBI3 (low vs. high) & $<0.001$ & 0.013 & 0.634 & $0.446-0.901$ & $<0.001$ & 0.001 & 0.452 & $0.290-0.704$ \\
\hline
\end{tabular}

Univariate analysis was calculated by the Kaplan-Meier method (the log-rank test). Multivariate analysis was done using the Cox multivariate proportional hazards regression model with stepwise manner (forward, likelihood ratio). AFP, $\alpha$-fetoprotein; $\gamma$-GT, $\gamma$-glutamyl transferase; TTR, time to recurrence; OS, overall survival; NS, not significant; NA, not applicable; HR, hazard ratio; CI, confidential interval.

\section{Discussion}

The results presented here demonstrated that EBI3 was a promising, independent predictor for survival and recurrence in $\mathrm{HCC}$ patients. In the present study, we investigated the expression of EBI3 in human HCC cell lines with low and high metastatic potential as well as resected cancer specimens. And we found that the patients with lower EBI3 expression had shorter survival times and higher recurrence rates after curative resection. In addition, tumor expression of EBI3 was an independent prognostic parameter for survival and recurrence after operation.
In the present study EBI3 downregulated expression had close relationship with malignant tumor characteristics, like tumor thrombus, poor differentiation and larger size. More importantly, our results demonstrated that downregulation of EBI3 may represent an early event in HCC development. It is an obvious advantage to predict the recurrence early for HCC patients after resection for response to any treatment and therefore for clinical outcome, particularly for HCC patients in early stage (21). For those in advanced stage, the present vascular invasion and multinodularity has yet been adverse predictors for prognosis established well after resection (22). Nevertheless, prognosis for HCC in early stage is not homogenous at all, and is short of 

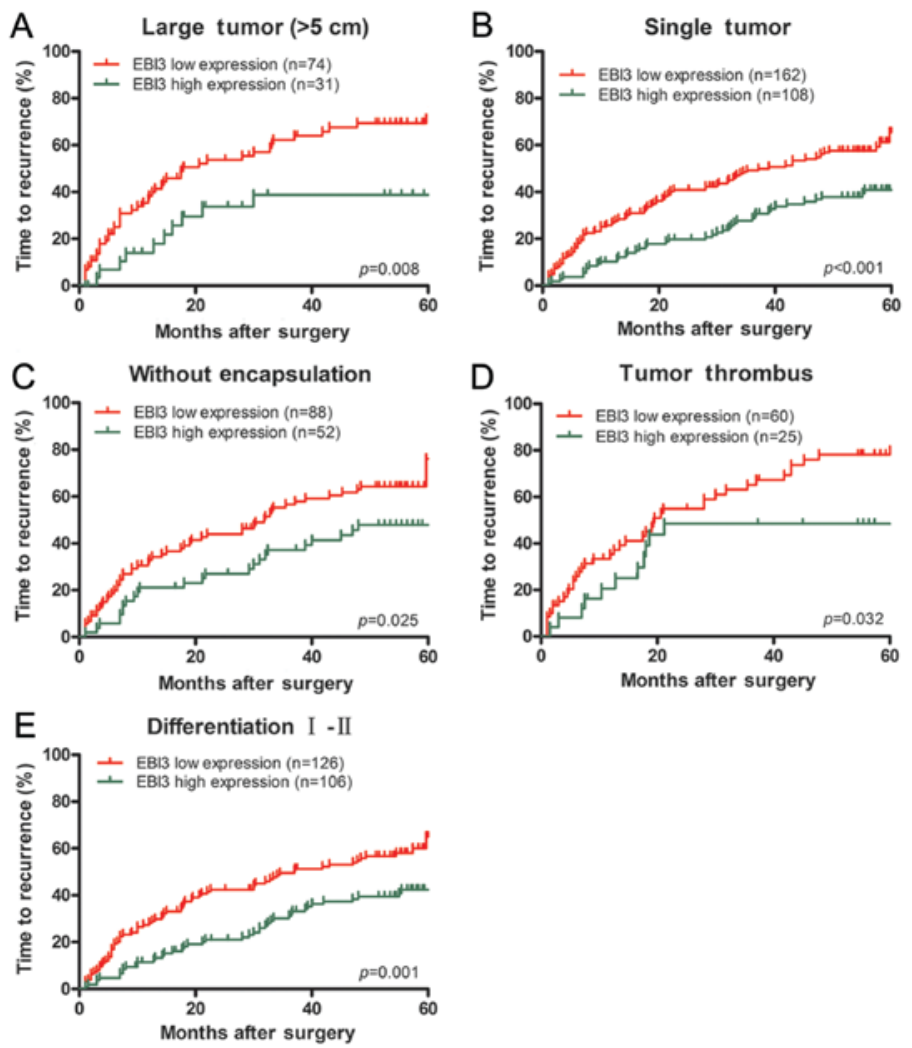

Figure 3. Subgroup analysis of EBI3 expression in relation to TTR. In term of time to recurrence, subgroup analysis indicated that EBI3 had prognostic value when classified by the following variables: large tumor $(>5 \mathrm{~cm})(\mathrm{A})$, single tumor (B), tumor without encapsulation (C), tumor thrombus (D) and tumor differentiation grade (I-II) (E). EBI3, Epstein-Barr virus-induced gene 3; TTR, time to recurrence.
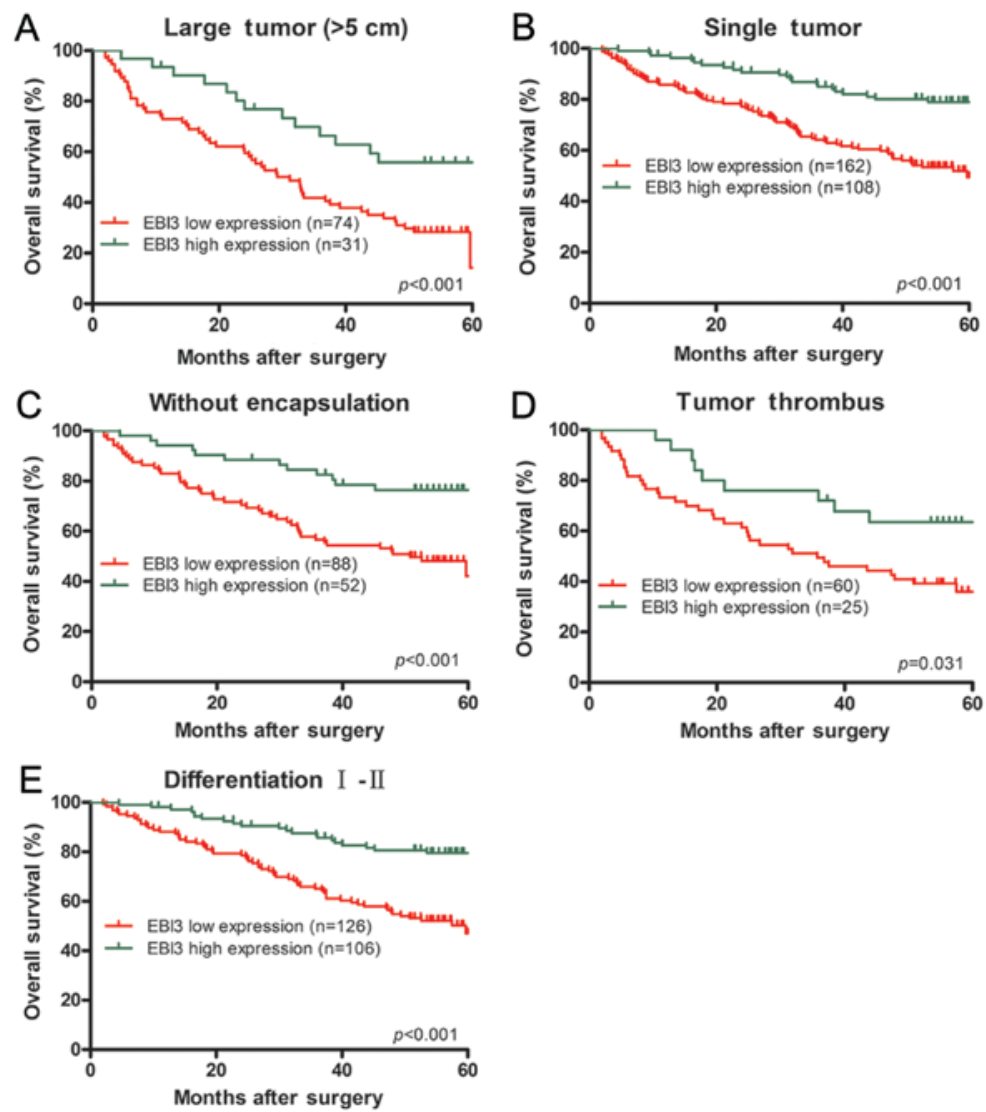

Figure 4. Subgroup analysis of EBI3 expression in relation to OS. In term of overall survival, subgroup analysis indicated that EBI3 had prognostic value when classified by the following variables: large tumor ( $>5 \mathrm{~cm}$ ) (A), single tumor (B), tumor without encapsulation (C), tumor thrombus (D) and tumor differentiation grade (I-II) (E). EBI3, Epstein-Barr virus-induced gene 3; OS, overall survival. 
clinicopathological indicators. For those early stage HCC (BCLC A stage) patients, $\mathrm{EBI} 3$ revealed the ability in predicting the risk of recurrence and patient survival. The independent prognostic value of EBI3 in HCC patients with early stage is of clinical importance. EBI3 low expression is related with pathogenesis of $\mathrm{HCC}$, and it may be an independent poor prognostic factor for HCC. In this regard, EBI3 may be a cancer suppressor gene of HCC and a potential molecular therapeutic target.

The reports of expression pattern and prognostic information on EBI3 in cancers are few and inconsistent. Up to now, it has been reported that immunoreactivity for EBI3 was predominantly expressed in the cytoplasm of cervical cancer (12), breast cancer (23) and lung cancer cells (10), and not in the nuclei of cancer and stromal cells. Zhang et al (13) reported that EBI3 was also over-expressed in the cytoplasm of the nasopharyngeal carcinoma cells. Our findings are in consistent with these observations previously reported. However, Wang et al (15) demonstrated that IL-35 was mainly detected in the stromal cells with various shapes rather than in nasopharyngeal carcinoma and skin melanoma cells. Thus, EBI3 may be detected in various human cancer tissues and are likely of multiple cellular sources. Moreover, high expression of EBI3 in many types of human cancers has been shown to be associated with poor prognosis. It was recently reported that the expression level of IL-35 in HCC tissues is similar to paratumour tissues (17). And HCC patients with high intratumoral IL-35 expression are related with significantly poorer recurrence-free survival and OS than low IL-35 expression patients. Furthermore, in multivariate analysis, IL-35 was found to be an independent prognostic factor for recurrence-free survival but not for OS. Interestingly, Long et al (18) found that the low expression of IL-35 in tumoral tissues seems contribute to the progression of HCC. And they showed that expression levels of IL-35 are significantly higher in the peri-tumoral tissue than the tumoral tissue. Similarly, significantly lower level expression of IL-35 was observed in HCC patients with larger tumor size, higher histological grades, positively microvascular invasion and lymph node. In the present study, we found that EBI3 expression was predominantly downregulated in $\mathrm{HCC}$ tumor tissues in comparison to peritumoral liver tissues, and low expression of EBI3 was related with unfavorable TTR and OS in HCC patients. We also found that the expression of IL-12p35, one of subunits of IL-35, is not been detected in the HCC tissues. Although IL-12p35 positive expression was associated with a worse survival in nasopharyngeal carcinoma, multivariate analyses suggested EBI3 rather than IL-12p35 was an independent prognostic marker (13). We assumed that EBI3 may be as a main functional subunit and plays a major role in IL-35, and has different impacts on prognosis based on tumor type.

In spite of our findings, limitations of our research need to be addressed. We lacked in vitro data to verify our results and although we did examine the function of EBI3 in the HCC cell lines, further studies are necessary to investigate the underlying mechanisms by which EBI3 influences the invasion and metastasis of cancer cells.

\section{Acknowledgements}

The present study was funded by National Natural Science Foundation of China (grant nos. 81572390 and 31300942),
Project of Nantong Science and Technology Bureau, Jiangsu Province, China (grant no. MS22015116). The present study was supported by the Clinical Biobank at Nantong University Affiliated Hospital in Jiangsu, China.

\section{References}

1. Sun YF, Xu Y, Yang XR, Guo W, Zhang X, Qiu SJ, Shi RY, Hu B, Zhou J and Fan J: Circulating stem cell-like epithelial cell adhesion molecule-positive tumor cells indicate poor prognosis of hepatocellular carcinoma after curative resection. Hepatology 57: 1458-1468, 2013.

2. Chen R, Cui J, Xu C, Xue T, Guo K, Gao D, Liu Y, Ye S and Ren Z: The significance of MMP-9 over MMP-2 in HCC invasiveness and recurrence of hepatocellular carcinoma after curative resection. Ann Surg Oncol 19 (Suppl 3): S375-S384, 2012.

3. Hanahan D and Weinberg RA: Hallmarks of cancer: The next generation. Cell 144: 646-674, 2011.

4. Horlad H, Ma C, Yano H, Pan C, Ohnishi K, Fujiwara Y, Endo S, Kikukawa Y, Okuno Y, Matsuoka M, et al: An IL-27/Stat3 axis induces expression of programmed cell death 1 ligands (PD-L1/2) on infiltrating macrophages in lymphoma. Cancer Sci 107: 1696-1704, 2016.

5. Collison LW, Delgoffe GM, Guy CS, Vignali KM, Chaturvedi V, Fairweather D, Satoskar AR, Garcia KC, Hunter CA, Drake CG, et al: The composition and signaling of the IL-35 receptor are unconventional. Nat Immunol 13: 290-299, 2012.

6. Vignali DA and Kuchroo VK: IL-12 family cytokines: Immunological playmakers. Nat Immunol 13: 722-728, 2012.

7. Ma Y, Chen L, Xie G, Zhou Y, Yue C, Yuan X, Zheng Y, Wang W, Deng L and Shen L: Elevated level of interleukin-35 in colorectal cancer induces conversion of $\mathrm{T}$ cells into $\mathrm{i} \operatorname{Tr} 35$ by activating STAT1/STAT3. Oncotarget 7: 73003-73015, 2016.

8. Olson BM, Jankowska-Gan E, Becker JT, Vignali DA, Burlingham WJ and McNeel DG: Human prostate tumor antigen-specific $\mathrm{CD} 8+$ regulatory $\mathrm{T}$ cells are inhibited by CTLA-4 or IL-35 blockade. J Immunol 189: 5590-5601, 2012.

9. Liang Y, Chen Q, Du W, Chen C, Li F, Yang J, Peng J, Kang D, Lin $\mathrm{B}$, Chai X, et al: Epstein-Barr virus-induced gene 3 (EBI3) blocking leads to induce antitumor cytotoxic T lymphocyte response and suppress tumor growth in colorectal cancer by bidirectional reciprocal-regulation STAT3 signaling pathway. Mediators Inflamm 2016: 3214105, 2016.

10. Nishino R, Takano A, Oshita H, Ishikawa $\mathrm{N}$, Akiyama $\mathrm{H}$, Ito $\mathrm{H}$, Nakayama H, Miyagi Y, Tsuchiya E, Kohno N, et al: Identification of Epstein-Barr virus-induced gene 3 as a novel serum and tissue biomarker and a therapeutic target for lung cancer. Clin Cancer Res 17: 6272-6286, 2011.

11. Fan YG, Zhai JM, Wang W, Feng B, Yao GL, An YH and Zeng C: IL-35 over-expression is associated with genesis of gastric cancer. Asian Pac J Cancer Prev 16: 2845-2849, 2015.

12. Hou YM, Dong J, Liu MY and Yu S: Expression of Epstein-Barr virus-induced gene 3 in cervical cancer: Association with clinicopathological parameters and prognosis. Oncol Lett 11: 330-334, 2016.

13. Zhang Y, Sun H, Wu H, Tan Q and Xiang K: Interleukin 35 is an independent prognostic factor and a therapeutic target for nasopharyngeal carcinoma. Contemp Oncol (Pozn) 19: 120-124, 2015.

14. Jin P, Ren H, Sun W, Xin W, Zhang H and Hao J: Circulating IL-35 in pancreatic ductal adenocarcinoma patients. Hum Immunol 75: 29-33, 2014.

15. Wang Z, Liu JQ, Liu Z, Shen R, Zhang G, Xu J, Basu S, Feng Y and Bai XF: Tumor-derived IL-35 promotes tumor growth by enhancing myeloid cell accumulation and angiogenesis. J Immunol 190: 2415-2423, 2013.

16. Zeng JC, Zhang Z, Li TY, Liang YF, Wang HM, Bao JJ, Zhang JA, Wang WD, Xiang WY, Kong B, et al: Assessing the role of IL-35 in colorectal cancer progression and prognosis. Int J Clin Exp Pathol 6: 1806-1816, 2013.

17. Fu YP, Yi Y, Cai XY, Sun J, Ni XC, He HW, Wang JX, Lu ZF, Huang JL, Cao Y, et al: Overexpression of interleukin-35 associates with hepatocellular carcinoma aggressiveness and recurrence after curative resection. Br J Cancer 114: 767-776, 2016.

18. Long J, Guo H, Cui S, Zhang H, Liu X, Li D, Han Z, Xi L, Kou W, $\mathrm{Xu} \mathrm{J}$, et al: IL-35 expression in hepatocellular carcinoma cells is associated with tumor progression. Oncotarget 7:45678-45686, 2016. 
19. Wu H, Shi XL, Zhang HJ, Song QJ, Yang XB, Hu WD, Mei GL, Chen X, Mao QS and Chen Z: Overexpression of ST3Gal-I promotes migration and invasion of HCCLM3 in vitro and poor prognosis in human hepatocellular carcinoma. Onco Targets Ther 9: 2227-2236, 2016.

20. Huang J, Fan X, Wang X, Lu Y, Zhu H, Wang W, Zhang S and Wang Z: High ROR2 expression in tumor cells and stroma is correlated with poor prognosis in pancreatic ductal adenocarcinoma. Sci Rep 5: 12991, 2015.

21. Qi X, Jia J, Fan D and Han G: Brivanib for hepatocellular carcinoma trials: Selection bias from barcelona clinic liver cancer stage? J Clin Oncol 32: 968, 2014.
22. Lim KC, Wang VW, Siddiqui FJ, Shi L, Chan ES, Oh HC, Tan SB and Chow PK: Cost-effectiveness analysis of liver resection versus transplantation for early hepatocellular carcinoma within the Milan criteria. Hepatology 61: 227-237, 2015.

23. Chen G, Liang Y, Guan X, Chen H, Liu Q, Lin B, Chen C, Huang M, Chen J, Wu W, et al: Circulating low IL-23: IL-35 cytokine ratio promotes progression associated with poor prognosisin breast cancer. Am J Transl Res 8: 2255-2264, 2016.

(i) $\odot$ This work is licensed under a Creative Commons Attribution-NonCommercial-NoDerivatives 4.0 International (CC BY-NC-ND 4.0) License. 